\title{
Rethinking Migration: New Theoretical and Empirical Perspectives
}

\author{
Alejandro Portes and Josh DeWind (Eds.) \\ New York and Oxford: Berghahn Books, 2007 \\ ISBN: 9781845453473 \\ $\$ 85.00$ (Hardcover), 453 pages
}

\author{
Michael Haan \\ Department of Sociology \\ University of Alberta \\ E-mail: mhaan@ualberta.ca
}

\begin{abstract}
Although migration is not a new phenomenon, several contemporary aspects arguably warrant a reconsideration of its basic theoretical and empirical underpinnings. As only one example of this, in 2008 the province of Alberta admitted more temporary foreign workers than it did permanent immigrants, marking a watershed moment for both the province and country. Instead of aiming to build a new life in the host country, these workers instead aim to build a better life where they currently are, and have come to work in Alberta to enable this. Although labour migration to Alberta is not new (see Harry Hiller's latest book on this issue), the magnitude is. Much the same can be said for migrant workers in southern Ontario or British Columbia. Trends like these raise multiple questions, including: Can current theoretical frameworks account for trends like this? Is it sufficient to revise current frameworks, or is an entire theoretical overhaul necessary to understand contemporary migration? Is temporary migration historically anomalous, or is it here to stay?

Since 2007, the United Nations has organized yearly high-level dialogues to grapple with 'new migration' issues like the ones above. They hold sessions on topics like short-term stays, annual labour migration, and the varying degrees of responsibility that different levels of government have for new migrants. So far, the consensus here appears to be that the old models do not adequately explain or predict current trends, but that no suitable replacement yet exists.

With these considerations in mind, I was very excited to review Alejandro Portes and Josh DeWind's new edited collection. Rethinking migration: new theoretical and empirical perspectives. The editors have assembled an excellent collection of essays on the topic, and the result is a timely and important work on a topic of emerging importance.
\end{abstract}

CSP 2010, 37.1-2: 273-275 
In Part 1, Portes and DeWind set the stage by outlining how theory and research have progressed in the area of international migration. The second part of the collection contains four different articles that examine the relationship between states and political incorporation. Collectively, the authors in this section discuss the prospects for integration, how that integration might look, and whether there is increasing opportunity for regional movement, particularly in the European Union. Although the topics within the section differ, there is overarching agreement that migration is a positive thing, and that it is the responsibility of the state to determine how to best facilitate, rather than restrict, migrant movement.

The third section of the book looks at the conceptual reality of transnational communities. Nearly every ethno-racial migrant group is part of a broader diaspora, and the chapters here grapple with the implications of this. Identities, sense of belonging, and community, are inherently linked to both the local and the global, and the three chapters in this section wrestle with this seeming contradiction. My favourite chapter in this section was the one written by Peggy Levitt and Nina Glick Schiller, where they advocate for a rethinking of 'society' along lines that do not focus so heavily on geography. Rather than grapple with how to change the way we think about migrants, which is the most obvious and problematic solution, Levitt and Schiller propose that the permanent population changes the way it sees itself. Unfortunately, they provide little guidance into how this might be achieved.

Part 4 focuses on unauthorized immigration and the second generation, and contains what are probably the most technical chapters in the book. Douglas Massey and Chiara Capoferro first outline the problems with existing datasets in measuring undocumented migrants. They then use these deficiencies as a justificatory platform for their 'ethnosurvey.' The ethnosurvey is a multimethod, multilevel, technique for learning about populations not present in standard data sources. In Germany, Friedrich Heckmann tells us in chapter 10, illegal immigration is often temporary because of that country's comprehensive registration system. Since service receipt depends on registration, migrants have a powerful incentive to participate in Germany's registration system. Consequently, Heckmann argues, illegal immigration is often quite short-term, and often involves human smuggling. This is much more difficult to measure, but for those interested in current practices, Heckmann outlines how Germany measures these populations.

In a chapter that was interesting but somewhat out of place in this section, Hartmut Esser tackles the issue of whether new migrant flows require new theoretical developments. This topic has already generated quite a debate amongst immigration scholars, and in the end, Esser does call for a new theory. Oddly, however, the new theory he provides does not appear to be entirely new, and after reading the chapter over several times, I must confess that I am not completely clear on the details of what he proposes.

CSP 2010, 37.1-2: 273-275 
In the final section of the book appears two pieces on the role of religion in migration and integration studies. Charles Hirschman's entry shows how migrants use religion to tighten their shared identity and build community in the United States. Riva Kastoryano argues that religion has almost superseded ethnicity as a unifying force in France and Germany, at least for Muslims. This no doubt stems in part from the common experiences shared by the groups themselves in these countries, and it serves as a reminder of how important the context of reception is for understanding group integration. It also illustrates how important and pervasive religion remains as a unifying force.

Obviously, this book has many strengths. Most notably, it represents a much-needed attempt to open a dialog into the new aspects of migration and immigration in today's global era. A deliberate tension in the book concerns the differences in attitudes and policies in dealing with migration issues across the world, suggesting that there is not a one-size-fits-all strategy to deal with new migration. We instead see context-specific solutions and frameworks, suggesting that rethinking migration needs to occur within each country. At the same time, countries can learn from each other, and Rethinking Migration provides a good nodal point for this to begin.

One of the weaknesses of the collection concerns its lack of context. It begins rather abruptly, with Portes and DeWind referring to 'the handbook' and 'the conference at Princeton' in the first line of their introductory chapter, as though we should all know what these were. Continuing through Chapter 1 (and with the help of a search engine), I began to realize that 'the handbook' refers to Hirschmann, Kasinitz and DeWind's edited volume entitled Handbook of International Migration: The American Experience (1999, Russell Sage Foundation). The articles there came out of a conference held on Sanibel Island, Florida, in 1996, and the current volume is an important update to the 1999 publication. "The conference" was the Conceptual and Methodological Developments in the Study of International Migration, held at Princeton University in May 2003. To my knowledge, neither of these critical pieces of information appears in the text.

This, however, is a minor quibble about an excellent edited collection. The book will be of interest to scholars of immigration the world over. It would also be an excellent resource for a graduate course on immigration and migrant flows. 